\title{
Cheetah conservation in South Africa
}

Cheetahs should be conserved as drivers of biodiversity conservation and as instruments of nature based tourism development. Only 7500 cheetahs remain worldwide and their numbers continue to

decrease. The species is currently listed as vulnerable, but is close to re-listing as endangered. In South Africa the distribution has shrunk from covering the whole country with the exception of forest to a narrow

band along the Northern border from Kgalagadi to Kruger. In addition, 38 fenced reserves have successfully reintroduced the cheetah. The main threats in South Africa are direct persecution, loss of prey base and habitat, illegal trade and inbreeding.

The cause for persecution is a perceived conflict with livestock and wildlife ranching.

\section{Kenneth Buk and Kelly Marnewick}

Kenneth Buk is a wildlife ecologist. Kelly Marnewick is a manager at the Centre of Wildlife Management at the University of Pretoria,.

\section{Why Conserve Cheefahs?}

Why be preoccupied with the status of one single species when so much biodiversity is threatened? Cost-efficient conservation usually takes a habitat, ecosystem or biodiversity approach, but in the case of the cheetah (Acinonyx juba$t u s)$ there are good reasons to be concerned with a single species. The cheetah is a charismatic flagship species with a big potential for tourism-financed conservation and associated job creation. It is an umbrella species that requires large areas of natural or near-natural habitats, which will help protect many species and habitats. As a top predator it is a keystone species and an indicator species of a wellconserved, functioning ecosystem. Hence, the cheetah contributes to both biodiversity conservation and economic development.

\section{Distribution and Numbers}

\section{Historical Distribution}

There are few historical records of cheetah distribution in Africa. Marker (1998) $)^{1}$ was of the opinion that historically the species was widely distributed throughout the continent in all 
Figure 1 The current distribution of cheetah in South Africa

(The named sites are fenced reserves where cheetahs have been released)

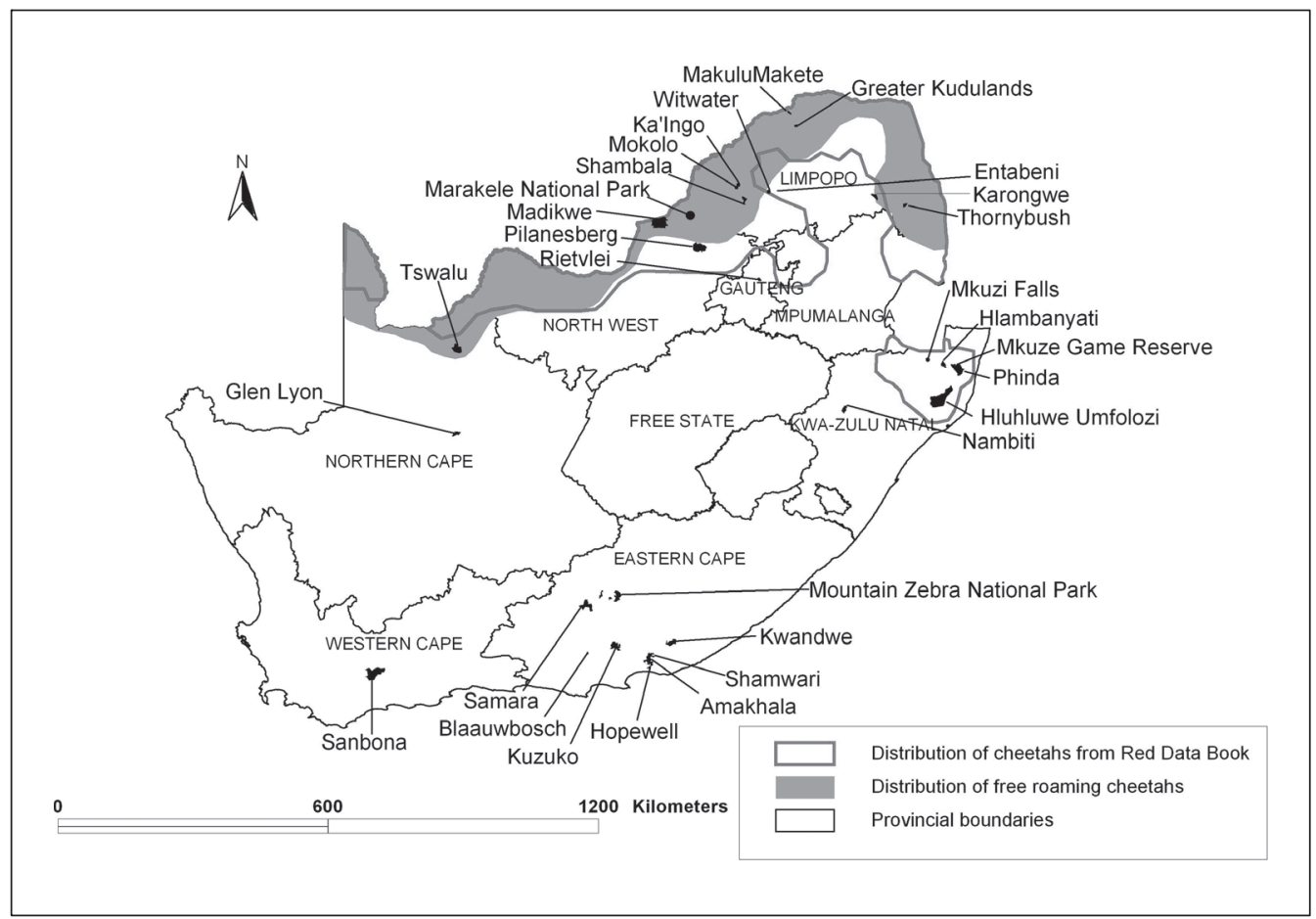

Source:

suitable habitats (see below) from the Cape to the Mediterranean.

In South Africa cheetahs were reported to be locally common in the Northern Cape province around 1840 (Backhouse 1844). ${ }^{2}$ In the 1860-70's normal cheetahs and an aberrant 'woolly' cheetah were reported from the Beaufort West area in the Western Cape province (Skinner and Smithers 1990; Sclater 1877). ${ }^{3}$ Cheetahs were exterminated from the Kwa-Zulu Natal province by the 1930s (Skinner and Smithers 1990), but were still reported from the Bushmanland and Kenhardt districts, Northern Cape in 1942 (Shortridge). ${ }^{4}$

By 1990 Skinner and Smithers (1990) reported cheetah distribution as sporadic in the Kgalagadi Transfrontier Park, parts of the North-West Province, northern Limpopo province, Kruger National Park in Mpumalanga and with small re-introduced populations in the Kwa-Zulu Natal reserves.

Qualified population estimates are still unavailable for some areas. However, the world population of cheetahs (Acinonyx jubatus) is estimated to have declined by $50 \%$ in 25 years from 1973 to 1998 to around 10000 animals (Marker, 1998). ${ }^{5}$ The population continued to decrease fast in recent years, with the population dropping another $25 \%$ to 7500 cheetahs from 1998 to 2008 (Bauer et al. 2008). ${ }^{6}$

\section{Current Distribution and Conservation Status}

Marnewick et al. (2007) ${ }^{7}$ collected distribution data by questionnaire surveys, complaint records and informal reports of cheetah 
sightings. Cheetah distribution (figure 1) currently stretches in an up to $200 \mathrm{~km}$ wide band along South Africa's northern borders from Kgalagadi Transfrontier Park to Kruger National Park. In addition, there have been successful cheetah re-introductions into about 38 fenced parks and reserves around South Africa, most of them located in NorthWest, Limpopo, KwaZuluNatal and Eastern Cape Provinces (Figure 1).

The Kruger National Park and Kgalagadi Transfrontier Park with their large sizes and pristine savanna are the most important formal conservation areas for cheetah in South Africa. The generally dense woody layer in Kruger does not provide ideal hunting opportunities for cheetah. However, it does provide good cover for hiding from a high density of lions and spotted hyaenas, reducing the risk of having kills stolen (Mills, Broomhall and du Toit, 2003) ${ }^{8}$ and possibly also getting killed (Mills and Funston, 2003). ${ }^{9}$ Kruger's $20,000 \mathrm{~km}^{2}$ of near pristine ecosystem holds about 200 cheetahs. Pienaar $(1963)^{10}$ reported 219 cheetahs in Kruger in 1963 and 263 in 1969 (Pienaar 1969) ${ }^{11}$ based on log books from rangers. A photographic cheetah census in 1991 identified 172 individuals: 82 in the Southern District, 60 in the Central District and 30 in the Northern District (Bowland and Mills, 1994). ${ }^{12}$

The Kgalagadi Transfrontier Park covers an area of $27000 \mathrm{~km}^{2}$ of arid savanna in Botswana and $9600 \mathrm{~km}^{2}$ in South Africa. A survey of visitors' photos identified 80 cheetahs made up of 31 males, 19 females, 4 unknown and 26 cubs (Knight 1999). ${ }^{13}$ Visitors almost exclusively had access to the South African side of the park, so the number is an underestimate of the total park population, but current field work indicates it may still be a valid estimate of the South African part of this population (Dr Gus Mills, Personal comment).

The Red Data Book of the Mammals of South Africa (Friedmann and Daly 2004) ${ }^{14}$ classifies cheetahs as vulnerable, due to an estimated population size of breeding individuals of just more than 250. However, it was noted that with the available data, the cheetahs were close to being classified as endangered. The main threats were identified as direct loss or exploitation, especially outside conservation areas.

\section{Threats}

\section{Habitat Loss}

Cheetahs potentially inhabit any area with prey of the preferred size - being 23 to $56 \mathrm{~kg}$ (Hayward et al., 2006) - and vegetation open enough to allow high-speed pursuit, although they seem to prefer habitat with some cover for approaching prey undetected. Thus, prior to recent extinctions cheetahs must have been found throughout Karoo / dwarf shrubland (Smithers, 1983), ${ }^{15}$ semidesert, grasslands and any savanna type with a fairly open ground storey. This includes miombo woodland areas where cheetahs pursue prey on dambos (drainageline grasslands) or adjacent flood plains, but conduct other activities in the woodland itself (Eaton, 1974; Purchase, 1998). ${ }^{16}$ The closed forest biome is avoided, whereas dense shrub-land is not conducive to hunting, potentially causing eye trauma (Bauer, 1998). ${ }^{17}$ South African cheetahs currently occur almost exclusively in the savanna biome. One probable reason is that in the more open biomes it has been easy for humans to spot and eradicate cheetahs and much of their prey. Another reason could be that wildlife ranching has expanded mostly in the savanna biome, and that cheetah recolonization has occurred from Zimbabwe and Botswana.

Several national parks and other conservation areas are found in the savanna biome, but half of the savanna vegetation types have less than $5 \%$ of their area protected in reserves (Low 
and Rebelo, 1998). ${ }^{18}$ However, where sustainable stocking levels are maintained on private ranches, the habitat can be considered intact. Most of the savanna biome is utilized for livestock and wildlife ranching, whereas cultivation and urbanization account for a smaller part. This highlights the importance of ranch owners in the long-term conservation of the savanna biome and cheetahs in South Africa.

\section{Land Use Changes Over the Past Two Decades}

South Africa's national parks have increased in total size over the past 15 years and will hopefully continue to do so. However, South Africa's human population is growing at a rate of $0.8 \%$ per year (CIA, 2008), so more cultivation as well as conflict between humans and wildlife is expected outside and along the parks. Reallocation of land to black farmers is scheduled to increase from $3 \%$ to $30 \%$ of arable land by 2014 according to government policy. Also, several completed and pending land claims are affecting national parks, conservation areas and wildlife ranches.

Over the past 20 years, there has been a shift from livestock to wildlife ranching in some parts of South Africa, especially in the Limpopo province. In 2001 there were 5061 wildlife ranches in South Africa covering an area of 10364154 ha or $8.5 \%$ with 3325652 ha in Limpopo Province (Bothma, 2005). ${ }^{19}$ Conversion from livestock to wildlife ranching takes place at a rate of 2 to $2.5 \%$ per annum in Limpopo, where the ecological and economic advantages of land use change are particularly pronounced (Bothma, 2005).

The conservation of savanna on private land may be jeopardized by rising food and biofuel prices, which will provide a strong incentive to cultivate vast areas not previously profitable for cultivation. In conclusion, although much suitable cheetah habitat remains in South Africa, increases in human population and crop prices as well as land reallocation, makes it important to work out measures to alleviate these impacts on wildlife and biodiversity.

\section{Persecution and Prey Depletion}

Direct persecution tops the list of factors leading to the recent population decline in cheetahs. In Namibia, where farmers can legally remove (i.e. kill or export) cheetahs, 'well over 10 000' have been removed from 1980 to 1998 (Marker and Schumann, 1998). ${ }^{20}$ The scale of persecution in South African is discussed below.

Prey depletion can be another cause of population decline. Across nine protected areas, where prey density should be at natural levels, cheetah biomass was significantly positively correlated with density of medium sized prey (15 to $60 \mathrm{~kg}$ ) (Laurenson, 1995). ${ }^{21}$ This shows how important a sufficient prey base is to cheetah survival, but it is unclear whether prey would be a limiting factor on South African livestock ranches.

Most of South Africa's potential cheetah habitat occurs outside conservation areas on privately owned livestock and wildlife ranches. However, on the livestock ranches cheetahs are killed under suspicion of killing young livestock, and on the majority of wildlife ranches, where the main source of income is hunting and live sale of antelopes, cheetahs are also persecuted.

The most common method used to eliminate cheetahs is to shoot on sight, but reports of running over with vehicles, trapping then shooting, gin traps, snares and poisoning have been received (Marnewick et al., 2007). ${ }^{22}$ Quantifying the extent of these killings is difficult as it is illegal to kill cheetahs in South Africa.

However, of the 199 landowners interviewed in the Thabazimbi district of the Limpopo province $71 \%$ of them perceived cheetahs to be a liability and had killed at least 26 cheetahs 
from 1999 to 2001. Further interviews in the Lephalale district indicated that $48.6 \%$ of the landowners $(N=89)$ who had cheetahs on their property perceived cheetahs as a liability, while $25.7 \%$ felt cheetahs were assets. In the Vhembe district ( $N=72$ ), the numbers were $34.4 \%$ and $28.0 \%$, respectively (Marnewick et al., 2007). ${ }^{23}$ In the Bray area of the North West Province, $88 \%$ of the landowners perceived cheetahs as a liability and $50 \%$ had removed cheetahs from their property (Marnewick et al., 2007).

In contrast, in the Bela-Bela (formerly Warmbaths) area of the Limpopo province, $57 \%$ of respondents felt that cheetahs were assets to them. This reflects that ecotourism is one of the main land uses in the area, with hunting and live sales being less important than in the other study areas.

Outside conservation areas, little information is available on what South African cheetahs actually do kill. Wilson $(2005)^{24}$ did a small study on scat content in the Thabazimbi area and found that $49 \%(n=19)$ of the scats contained duiker Silvicapra grimmia hair and $24 \%(n=9)$ of the scats contained impala hair. Predation on livestock does occur, but is not common. In the Thabazimbi district, one domestic calf was killed and one cheetah was trapped at a goat kraal. In Lephalale, one landowner with a permit, shot a cheetah in a kraal and another in Alldays reported losing sheep in the kraal. Very few reports of cheetah predation on livestock have been positively confirmed (Marnewick et al. 2007). ${ }^{25}$

Wildlife ranchers report high rates of cheetah predation on blesbok (Damaliscus dorcas phillipsi) and ostrich (Struthio camelus) populations, while coalitions of cheetahs can take prey as large as mature kudu cows and waterbuck. Ostrich and impala have been the most commonly observed prey species (Marnewick et al. 2007).
The cheetah diet in conservation areas usually consists of small-medium sized mammals and the young of larger species - from springhares (Pedetes capensis) to giraffe (Giraffa camelopardalis) - but often dominated by the most common antelope species in the home range (Hayward et al., 2006). ${ }^{26}$ Cheetahs show preference for prey from 23 to $56 \mathrm{~kg}$, but impala (Aepyceros melampus) and blesbok are the only species significantly preferred when analyzed across a range of reserves (Hayward et al. 2006). For instance in Kruger 45 to $68 \%$ of the prey is impala (Pienaar 1969, Mills, Broomhall and du Toit 2003). ${ }^{27}$

\section{Predators}

Cheetahs can suffer very high mortality from other predators. An extreme case is the Serengeti Plain (Tanzania), where other predators, mostly lion and spotted hyena, kill about $70 \%$ of cheetahs before reaching independence (Laurenson, 1995).$^{28}$ Also, other predators may klepto-parasitize on cheetahs; that is steal the prey the cheetah has spent considerable energy subduing. Laurenson (1995) showed that cheetah biomass was significantly negatively correlated with lion biomass across nine protected areas (Laurenson, 1995).

Therefore, ranches or reserves stocked with wildlife, but with an absence or low density of lion (Panthera leo), spotted hyaena (Crocuta crocuta) and leopards (Panthera pardus) can be more conducive to cheetah than national parks, if only the cheetahs are not persecuted (McVittie 1979; Laurenson, Wielebnowski and Caro 1995) ${ }^{29}$ The suitability of wildlife ranches and the cheetah's wide ranging patterns makes it all the more important to protect the species beyond conservation areas. Another implication of heavy natural predation on cheetah is 
that providing artificial water throughout conservation areas may augment numbers of elephants, common antelopes, lions and spotted hyena, but at the expense of cheetah and other species.

\section{Genetics and Health}

The cheetah exhibits significantly lower heterozygosity than other cats (O'Brien et al., 1983; Newman et al., 1985). ${ }^{30}$ It is almost monomorphic for conventional coding loci on which the domestic cat (Felis silvestris) shows $7.0 \%$ heterozygosity. On mini and microsatellite loci cheetahs have 90 and $51 \%$, respectively, of the heterozygosity found on the same loci in the domestic cat (Menotti-Raymond and O'Brien, 1995). ${ }^{31}$ Possibly as a consequence of the lowered heterozygosity about $70 \%$ of cheetah sperm is morphologically abnormal compared to $21 \%$ in the domestic cat (Wildt et al., 1983; Lindburg et al., 1993). ${ }^{32}$

How the lowered heterozygosity has arisen, as well as what present and potential implications it has for cheetah conservation have been the topic of a heated debate. O'Brien argues that a series of population bottlenecks has caused the loss of genetic variability (O'Brian et al., 1983; Menotti-Raymond and O'Brien, 1995). ${ }^{33}$ Several cheetah researchers and geneticists question this scenario based on the severity of the bottleneck needed (Caro, 1994; Merola, 1994). ${ }^{34}$ Hedrick (1996) ${ }^{35}$ instead suggests the lowered heterozygosity is the consequence of a metapopulation structure. Merola (1994) points out that lowered heterozygosity seems to be normal in some species without signs of past bottlenecks.

O'Brien $(1994,1998)^{36}$ argues that the lowered heterozygosity and higher rate of abnormal sperm currently have effects on congenital juvenile mortality, male fertility as well as morbidity and mortality from numerous diseases, all in captivity. High heterozygosity is believed to be very important to disease resistance in individual animals and in populations. With high heterozygosity more forms of host immuno molecules potentially attaching to the surface of an infective agent will be present in the host. This reduces the chance of an infectious agent having or evolving a form unmatched by the host. High heterozygosity also makes more genetic combinations available for evolution of a novel immune response in the host.

In response to O'Brien several cheetah researchers point out that (a) problems of juvenile mortality and infertility in captive cheetah vary strongly between captive facilities and are due to part inexperience in animal husbandry and part cases of inbreeding (Merola, 1994; Wielebnowski, 1996); ${ }^{37}$ (b) that there are no problems with fertility in the wild (Caro, 1994), ${ }^{38}$ and (c) in the wild, juvenile mortality possibly attributable to lowered heterozygosity is at normal levels (Laurenson et al., 1995). ${ }^{39}$

Numerous diseases and health problems have been recorded in cheetahs (Munson et al., 1998; Kriek et al., 1998; van Vuuren et al., 1998; Lobetti et al., 1998; Terio et al., 1998; Picard et al., 1998; Phillips, 1993; Phillips et al., 1993; Peirce et al., 1995; Heeney et al., 1990; Brown et al., 1993; Boomker and Henton, 1980; Bond and Lindburg, 1990; Lindburg et al. 1993; Keet et al., 1997). ${ }^{40}$ However, the three most common diseases in captivity have not been recorded in the wild nor have many of the others. This supports the opinion of several cheetah researchers that most of the diseases occurring in captivity are due to the stress, high density and unnatural behaviour and diet associated with captivity (Munson et al., 1998; Kriek et al., 1998; van Vuuren et al., 1998; Lobetti et al., 1998; Terio et al., 1998; Picard et al. 1998; Caro, 1994). ${ }^{41}$ To date epidemics are not known from wild cheetahs, even where epidemics have been recorded 
in other carnivores (Caro, 1994), whereas at least one epidemic of feline infectious peritonitis (FIP) with $60 \%$ mortality has occurred in captivity (Caro, 1994). Major research priorities therefore include evaluating the role of stress in captive cheetah diseases, documenting disease prevalence in captive and wild cheetah and research on prevention and treatment.

Regardless of the controversy surrounding the origin and present symptoms of comparatively low heterozygosity, there is consensus that the recent population decline is not due primarily to genetic problems (O'Brien, 1998), ${ }^{42}$ but that lowered heterozygosity could potentially cause infertility, congenital defects, susceptibility to disease and failure to adapt to environmental changes. Therefore cheetah populations should be monitored continuously and management should prevent loss of existing heterozygosity. Avoiding local and global population bottlenecks as well as inbreeding is therefore even more crucial in cheetahs than in other threatened species.

\section{Trade in Cheetahs}

South African legislation allows captive bred cheetahs to be exported. The only requirement to prove captive bred status is that the cheetah is fitted with a microchip. A CITES permit is then issued and the cheetah is able to leave the country legally. There are currently no laws that demand DNA certificates to prove parentage. Captive breeding facilities in South Africa are not required to be members of ISIS (International Species Information System, www.isis.org) or any other recognized studbook. Only two captive breeding centres in SA are CITES accredited.

The wanting proof of captive bred status has led to wild cheetahs being caught in South Africa, and occasionally Botswana and Namibia, brought to certain breeding facilities in South Africa where they are microchipped and exported as captive bred animals to zoos and captive facilities internationally. Additionally, wild cheetahs are also trapped to begin new breeding programmes, which are seen to be economically lucrative. It is difficult to estimate how many cheetahs are traded illegally this way each year.

Legal international trade in cheetahs is conducted under the CITES convention. According to the CITES office the following number of cheetahs originating in South Africa were exported: 1996: 14, 1997: 36; 1998: 28; 1999: 29; 2000: 129; 2001: 26; 2002: 50; 2004: 45; 2005 : 44. Of the 129 exports in 2000 as many as 100 were body parts going to China for 'scientific purposes'.

\section{Unregulated Captive and \\ Metapopulation Breeding}

More than 500 cheetahs are in captivity at a minimum of 44 facilities in South Africa. Permits from the provincial conservation authority to hold cheetahs are the only requirement and have very few conditions attached. There is at present no legislation enforcing membership of a studbook, accurate data bases, breeding records or a co-ordinated conservation plan. Hence, most cheetahs in captivity are not contributing to a healthy, sustainable captive population. Furthermore, many facilities source their cheetahs from the wild, either legally or illegally, which impacts on the wild cheetah population. Additionally, the captive breeding industry is often used as a cover for the black market trade.

Currently, there is no formal plan for management of the meta-population of cheetahs populating smaller reserves around the country. Therefore, there is a very real risk that inbreeding and further loss of the very limited genetic diversity in cheetahs will occur. 


\section{Solutions to the Threats}

\section{Habitat Loss}

The loss of natural or semi-natural habitats is a general problem to the conservation of all biodiversity, and is strongly linked to the need for human population control. Setting aside more land for formal conservation, providing a conducive environment for the wildlife industry and promoting environmentally friendly practices on all land are among the more immediate solutions to this threat. Also, the production of biofuels should be discouraged in favour of more land-efficient, sustainable energy production such a solar, wind and ocean (wave, tide and current) power.

\section{Persecution and Prey Depletion}

\section{NCCF-SA Advisory Forum}

In 2000 concerned landowners, De Wildt Cheetah and Wildlife Trust, conservation authorities and organizations and other interested parties formed the National Cheetah Management Programme (NCMP), which evolved into National Cheetah Conservation Forum of South Africa (NCCF-SA). This is a consultatory forum for all issues surrounding cheetah conservation. Various subcommittees exist to deal with specific issues: the Relocation Committee, the Captive Breeders Committee, the Gene Flow Committee and the Education Committee. The NCCF-SA is involved in the guidance of government policy, development of best practice protocols and promotion of ethical practices.

\section{Translocation Scheme}

NCCF-SA decided that a translocation scheme was needed for cheetahs causing damage. The scheme compensates landowners with R10 000 for each live cheetah captured. The cheetahs are relocated into conservation areas, where they are monitored and confined by predator fencing. The receiver of the cheetah gives a minimum donation of R15 000 for the cheetah. The R5 000 balance covers holding the cheetah for a veterinary check up, fitting with a radio collar and habituation to people and vehicles. The scheme is thus financially self-sustaining, and the landowners welcomed the economic incentive for cooperation. The De Wildt Cheetah and Wildlife Trust houses and administers this fund on behalf of the NCCF-SA.

Relocation venues are required to submit a management plan, which must show that the reserve is ecologically able to hold cheetahs in a free-roaming situation for a minimum of two years without supplementing the prey population. They must also commit to a monitoring programme.

By the end of 2006, 137 cheetahs have been received through this programme. Five died and 16 had to be placed in temporary or permanent captivity, all due to injuries sustained during capture, while others were too young for immediate release. The 107 released cheetahs have produced 68 cubs. Although a short-term success, translocating cheetahs from ranch lands to a limited number of reserves cannot continue indefinitely. Other solutions need to be implemented to keep cheetahs on ranch lands.

\section{Conflict Prevention}

As a result of the successful Anatolian guard dog initiative implemented by the Cheetah Conservation Foundation in Namibia, a trial programme has been launched by Cheetah Outreach and the De Wildt Wild Cheetah Project to introduce the Anatolian to serve landowners of South Africa. The Anatolian guard dogs successfully guard livestock against cheetahs and other predators, and the predator populations find a balance with their natural prey. To promote a good working diet and veterinary care, 
the programme sponsors costs for the first year. The rest is in the hands of the landowner, who must invest interest during the initial critical period to ensure success in the rearing of a productive guarder.

Other successful means of conflict prevention include employing a herdsman, using protective collars, which cover the neck against bites, and using small predator proof enclosures at critical times such as at night and during lambing. Collars with deterring sound or scent, and other deterrents may also work, but tend to lose efficiency as the predator becomes habituated. Cell phone collars send an sms to the owner when the livestock runs, giving him a chance to respond to predation or livestock theft.

\section{Conflict Resolution}

The De Wildt Wild Cheetah Project responds to complaints from landowners by visiting on their properties, discussing their problems and solutions and showing the landowner how to identify the spoor and killing methods of the various predators. Capture is only used as a last resort where the landowner cannot be convinced to leave the cheetah on the property.

Workshops are also organised by the De Wildt Wild Cheetah Project in collaboration with other organizations and the attendees are given presentations not only on cheetahs, but also other predators, poison, birds, bush control, veld management, government policy and anything else pertinent to wildlife and cattle ranching.

'Cheetah Friendly' is an initiative developed by the NCCF-SA that promotes the formation of predator 'safe areas'. Landowners sign a pledge with very basic criteria to be Cheetah Friendly, if these are adhered to, then the land is generally predator friendly. In return the landowner gets a sign for his gate and a certificate for his lodge. This concept can be developed further to include marketing opportunities for the landowner as well as by educating consumers to use Cheetah Friendly areas for their hunting trips and holidays.

\section{Education / Outreach}

Several organizations deliver outreach programmes to local community schools and together reach approximately 36000 learners annually. Natural science curriculum-linked lesson plans use the cheetah as a learning tool and are introduced at intermediate phase. A live cheetah visits the school, and the unique beauty of this elegant, fragile predator leaves a lasting impression and builds a sense of pride and ownership of Africa's wildlife heritage.

\section{Research}

In order to understand and conserve cheetah outside protected areas, information is needed on their status, range use and impact on wildlife ranching. The De Wildt Wild Cheetah Project is running an intensive study of cheetahs outside conservation areas with the core study area in the Thabazimbi district of the Limpopo province. Questionnaire surveys, capture-recapture sampling using camera traps, conventional and genetic scat analysis and GPS/cell phonecollar studies are conducted. These studies have shown cheetahs using large ranges and that they are moving freely through the many game fences in the study area (Marnewick and Cilliers 2005). ${ }^{43}$ One cheetah may make use of 70 farms, and in many instances each of the 70 land owner are under the impression that they each have a different cheetah on their land. Hence the cheetahs are generally far less abundant and much more sensitive to persecution than recognised by the land owners.

Research on the conservation biology and management of cheetah in small reserves in South Africa is important to ensure reintroductions are as successful as possible, meta- 
populations are managed for genetic diversity, management problems are addressed and owners of potential cheetah reserves can be adequately advised and encouraged. Such research is planned under the auspices of De Wildt, but funding is still required.

In conclusion, livestock ranching can be in harmony with cheetahs provided proper mitigating measures are put in place, such as kraaling young animals and using guard animals. Wildlife properties can also support cheetah populations, but a higher tolerance and better understanding of cheetahs is required. In some cases, management efforts can reduce losses and make predators more welcome e.g. putting expensive antelope types like roan and sable in camps, keeping water holes away from fences and stocking antelope that are predator wise. Where feasible a switch to ecotourism, would make these properties excellent homes to cheetahs.

\section{Predators}

The threat posed by other predators is mainly a natural one, to which no direct response is appropriate. However, firstly cheetah conservation should be encouraged where there are few predators. Secondly, more research should be carried out on the relations between large predators, in particular in smaller reserves where cheetahs have been or are to be released. Thirdly, artificial water provisioning, especially in conservation areas, should be carefully considered, because of its effect on sensitive biodiversity, including cheetahs.

\section{Genetics and Health}

The National Cheetah Conservation Forum of South Africa (NCCF-SA) has been lobbying for compulsory membership to an international studbook as well as a regional DNA database for captive facilities in South Africa.
The captive breeders have since formed their own group, the South Africa Cheetah Breeders Association, but a South African studbook is still not in place. Relocated cheetahs should also be part of a studbook, and a meta-population management plan should be devised and implemented to avoid inbreeding.

Research on the role of stress in cheetah disease in captivity, and documentation of incidences and severity of diseases in captive and wild cheetahs should be given adequate support to continue.

\section{National Genetic Database (DNA Profiling)}

A National Genetic Database for cheetah has been established at the Agricultural Research Council (ARC) in conjunction with several universities. In this central database information on more than 360 captive and wild cheetahs in Southern Africa has been recorded with the co-operation of cheetah breeders, keepers and conservationists. Information stored in the Database includes the following:

- Birth date, sex, age, parents, place of birth, numbers born, population of origin, transponder number, etc.

- DNA profiles using micro-satellites and other genetic markers.

However, membership of this Database is voluntary and many captive breeders do not support it. This is reflected in the 360 samples in the database (which includes wild samples) and more than 500 cheetahs in captivity.

\section{Trade in Cheetahs and Unregulated Breeding}

Genetic proof of origin should be a prerequisite for any trade in cheetahs. Compulsory membership to an international studbook as well as a regional DNA database for captive facilities and small reserves in South Africa would ensure these populations contribute to the genetic 
pool. This along with husbandry regulations and full transparency would also significantly reduce the risk of captive facilities being used as fronts for illegal trade.

\section{The Most Important Steps for Conserving Cheetahs in South Africa}

1. Cheetah conflict resolution programme to interact with landowners in solving conflicts, recommend such ideas as livestock guarding dogs and promote Cheetah Friendly land management.

2. Eliminate the black market trade of cheetahs. This, to a large extent, will be achieved if the captive breeding industry is correctly regulated. This includes an audit of all facilities, a compulsory studbook and DNA database, development of breeding plans and conservation objectives as well as more effective permitting and control.
DNA certificates proving parentage should be compulsory for all cheetah sales and movements.

3. Develop and implement a meta-population management plan for cheetahs in isolated reserved and in captivity. These cheetahs represent a valuable genetic pool, which needs to be managed in order to avoid inbreeding and loss of genetic diversity.

4. Research on the conservation biology of cheetahs on ranches and on relocated cheetahs (typically in small reserves) to provide information for meta-population management, reducing mortality and conflicts and promoting cheetahs as an economic incentive for natural habitat protection.

5. Education of children, landowners and the general public. This must continue through the outreach programmes, media and workshops for landowners.

\section{Notes and References}

1 L Marker, and BD Schumann, 1998.

'Cheetahs as problem animals:

Management of cheetahs on private land in Namibia', in BL Penzhorn, (ed.), Proceedings of a Symposium on Cheetahs as Game Ranch Animals, South African Vet. Ass., Onderstepoort, 1998.

2 J Backhouse, A narrative of a visit to the Mauritius and South Africa. London, Adams \& Co,1844, in JD Skinner and RHN Smithers, The mammals of the Southern African sub-region, 1990 p 392.

3 Skinner and Smithers 1990 (See endnote "i above); PL Sclater, 'Felis lanea the woolly cheetah', Proceedings of the Royal Society of London, 1877 pp532-533 in Skinner, p 392.

4 GC Shortridge, Field notes on the first and second expeditions of the Cape Museums mammal survey of the Cape Province, and descriptions of some new subgenera and subspecies. Annals of the South African Museum vol 36, 1942, pp27-100. in Skinner, p 392.
5 L Marker, 'Current status of the cheetah (Acinonyx jubatus)', proceedings of a symposium on Cheetahs as Game Ranch Animals, Onderstepoort,1998 pp 1-17.

6 H Bauer, F Belbachir, S Durant, L Hunter, L Marker, K Packer, and N Purchase, 'Acinonyx jubatus. The IUCN redlist of threatened species.' 2008. http://www. iucnredlist.org/details/219.

7 K Marnewick, A Beckhelling, D Cilliers, E Lane, G Mills, K Herring, P Caldwell, R Hall, S Meinties 'The Status of the Cheetah in South Africa' CAT News Special Issue 3 - Cheetahs in Southern Africa, online, 2007.

8 MGL Mills, LS Brooomhall, and JT du Toit, 'Cheetah feeding ecology in the Kruger National Park and a comparison across African savanna habitats: is the cheetah only a successful hunter on open grassland plains?' Wildlife Biology, no 10: 2003, pp 177-184.

9 MGL Mills and PJ Funston 'Large carnivores and savanna heterogeneity', in T du Toit, KH Rogers and HC Biggs (eds), The Kruger experience: Ecology and management of savanna heterogeneity, Washington: , Island Press, 2003, pp 370-388.

$10 \mathrm{U}$ de V Pienaar,. 'The large mammals of the Kruger National Park - their distribution and present-day status,' Koedoe, no 6, 1963, pp 1-37.

11 U de V Pienaar, 'Predator-prey relationships amongst the larger mammals of the Kruger National Park.' Koedoe no 12, 1969, pp 108-176.

12 AE Bowland and MGL Mills, 'T'he 1990/1991 cheetah photographic survey.' Scientific Report 6/94. SANParks, Skukuza, 1994.

13 AK Knight, 'Cheetah numbers in a changing environment: Kalahari Gemsbok National Park', Endangered Wildlife Trust, Johannesburg, 1999.

14 Y Friedmann and B Daly, 'Red data book of the mammals of South Africa: a conservation assessment' CBSG Southern Africa, 
Conservation Breeding Specialist Group (SSC/IUCN), Endangered Wildlife Trust, South Africa. 2004, pp 147-149.

15 RHN Smithers,. The mammals of the southern African subregion, Pretoria: Uni. of Pretoria Press, South Africa, 1983.

16 RL Eaton, The cheetah: the biology, ecology and behavior of an endangered species. N.Y., U.S.A : Van Nostrand Reinhold, 1974: GK Purchase, 'The Matusadona Cheetah Project: lessons from a wild-towild translocation', in BL Penzhorn, (ed), Proceedings of a Symposium on Cheetahs as Game Ranch Animals. South African Vet. Ass. Onderstepoort, 1998.

17 GA Baver, 'Cheetah - running blind,' in BL (ed.), Penzhorn, 1998. Proceedings of a Symposium on Cheetahs as Game Ranch Animals. South African Vet. Ass., Onderstepoort. 1998

18 AB Low and AG Rebelo, 1996. 'Vegetation of South Africa, Lesotho and Swaziland,' Department of Environmental Affairs and Tourism, Pretoria

19 J du P Bothma, 'Extensive Wildlife Production in South Africa', keynote address: Wildlife Seminar, Northern Game Farmers' Organisation, Pretoria, 11 March 2005.

20 L Marker and B.D Schumann, 'Cheetahs as problem animals: Management of cheetahs on private land in Namibia,' in Proceedings of a Symposium on Cheetahs as Game Ranch Animals. South African Vet. Ass., Onderstepoort.

21 MK Laurenson, 'Implications of high offspring mortality for cheetah population dynamics', in ARE Sinclair and P Arcese, (eds) Serengeti Il: Research, conservation and management of an ecosystem, Chicago: University of Chicago Press, 1995.

22 Marnewick et al., 2007 (See endnote vii).

23 Ibid.

24 Wilson, 2005

25 Marnewick et al., 2007 (See endnote vi).

26 MW Hayward., M Hofmeyr, J O'Brien,. and GIH Kerley, 'Prey preferences of the cheetah (Acinonyx jubatus) (Felidae: Carnivora): morphological limitations or the need to capture rapidly consumable prey before kleptoparasites arrive?', J.Zoolog, no 270, 2006, pp 615-627.

27 Pienaar 1969 (see endnote 11); MGL Mills, LS Brooomhall and JT du Toit, 'Cheetah feeding ecology in the Kruger National Park and a comparison across African savanna habitats: is the cheetah only a successful hunter on open grassland plains?' Wildlife Biology, vol 10, 2003.177-184.

28 Laurenson, 1995 (See endnote ${ }^{\mathrm{xx}}$ ).

29 R McVittie, 1979. 'Changes in the social behavior of South West African cheetah', Madoqua vol 11, no 3, 171-184; MK Laurenson, N Wielebnowski, and TM.Caro, Extrinsic factors and juvenile mortality in cheetahs. Conservation Biology, vol 9, no 5, 1995, pp 1329-1331.

30 A Newman, M Bush, DE Wildt, D van Dam,., M. Frankehuis, , L.Simmons, , L.Phillips, and SJ O'Brien,. 'Biochemical genetic variation in eight endangered feline species', J. Mammal, vol 66, 1985, pp 256-267.

31 MA Menotti-Raymond and SJ O'Brien, 1995. 'Evolutionary conservation of ten microsatellite loci in four species of Felidae', J. of Heredity, vol 86, no 4, pp 319-322.

32 DE Wildt, M Bush, JG Howard, SJ O'Brien, D Meltzer, van A Dyk, H Ebedes and DJ Brand, 'Unique seminal quality in the South African cheetah and a comparative evaluation in the domestic cat', Biol. Reprod. vol 29, 1983, pp 1019-25; DG Lindburg, BS Durrant, SE Millard and JE Oosterhuis, 'Fertility assessment of cheetah males with poor seminal quality', Zoo Biol. vol 12, 1993, pp 97-104.

33 SJ O'Brien, DE Wildt, DGoldman, CR Merril, and M Bush, 'The cheetah is depauperate in genetic variation,' Science, vol 221, 1983,459-461; Menotti-Raymond and O'Brien, 1995, (See endnote xxx above).

34 M Merola, 'A reassessment of homozygosity and the case for inbreeding in the cheetah, Acinonyx jubatus: implications for conservation', Cons. Biol. vol 8 no 4, 1994, pp 961-971.

35 PW Hedrick, 'Bottleneck(s) or metapopulation in cheetahs', Cons. Biol. vol 10, no 3 , 1996, 897-899.

36 SJ O'Brien, 'Intersection of population genetics and species conservation - the cheetahs' dilemma', Evol. Biol, vol 30, 1998, pp 79-91.

37 M Merola, 'A reassessment of homozygosity and the case for inbreeding in the cheetah, Acinonyx jubatus: implications for conservation', Cons. Biol. vol 8, no 4,
1994, pp 961-971. N Wielebnowski, 'Reassessing the relationship between juvenile mortality and genetic monomorphism in captive cheetahs,' Zoo Biology vol 14, no 3, 1996, pp 53-369.

38 TM Caro, Cheetahs of the Serengeti Plains - Group living in an asocial species. Chicago:The Uni. of Chicago Press, 1994.

39 Laurenson, 1995 (See endnote ${ }^{x \times}$ )

40 L Munson, DGA Meltzer, HPJ Kriek, 'Diseases of the cheetah (Acinonyx jubatus)', in BL Penzhorn (ed), Proceedings of a Symposium on Cheetahs as Game Ranch Animals', South African Vet. Ass, Onderstepoort, 1998; NPJ Kriek, PS, Rogers, WA Schultheiss, M van Vuuren and WL Berry, 'Neonatal mortalities in captive-bred mortalities, in Proceedings of a Symposium on Cheetahs as Game Ranch Animals; M van Vuuren, TGoosen, and PS Rogers, 'Feline herpesvirus infection in agroup of semi-captive cheetahs' in Proceedings of a Symposium on Cheetahs as Game Ranch Animals; RG Lobetti, J Picard, NPJ Kriek, and PS Rogers, 'Prevalence of helicobacteriosis and gastritis in agroup of smei-captive cheetahs (Acinonyx jubatus) in South Africa', in Proceedings of a Symposium on Cheetahs as Game Ranch Animals. KA Terio, JV Solnick, and L Munson, 'Potential mechanisms underlying gastritis in cheetahs (Acinonyx jubatus)' in Proceedings of a Symposium on Cheetahs as Game Ranch Animals; JA Picard, E Lane, and M Louw, 'Cryptococosis in cheetahs', in Proceedings of a Symposium on Cheetahs as Game Ranch Animals; JA Phillips,. 'Bone consumption by cheetahs at undisturbed kills: Evidence for a lack of focal palatine erosion', J. Mamm. vol 74, no 2, 1993, pp 487-492; JA Phillips, MB Worley, D Morsbach, and TM Williams, 'Relationship among diet, growth and occurrence of focal palatine erosion in wild-caught captive cheetahs', Madoqua, vol 18, no 2, 1993, pp 79-83; MA Peirce, MK Laurenson, and SC Gascoyne, 'Hepatozoonosis in cheetahs and wild dogs in the Serengeti ecosystem', Afr. J. Ecol. vol 33, 1995, pp 273-275; JL Heeney, JF Evermann, AJ McKeirnan, L Marker-Kraus, ME Roelke, M Bush, DE Wildt, DG Meltzer, L Colly, J Lukas, , VJ Manton, TCaro, and SJ $\mathrm{O}$ 'Brien, 'Prevalence and implications of feline coronavirus infections of captive and free-ranging cheetahs (Acinonyx jubatus)', J.of Virology, vol 64, no 5, 1990, 
pp1964-1972; EW Brown, RA Olmsted, JS Martenson and SJ O'Brien, 'Exposure to FIV and FIPV in the wild and captive cheetahs', Zoo Biol. vol 12, 1993, pp 135-142; J Boomker, and MM Henton, 'Pseudotuberculosis in a cheetah (Acinonyx jubatus)' S.Afr.J.Wildl.Res. vol 10, 1980, 63-66. JC Bond and DG Lindburg, 'Carcass feeding of captive cheetahs (Acinonyx jubatus): the effects of a naturalistic feeding program on oral health and psychological well-being', Appl.Animal Behav. Sci. vol 26, 1990, pp 373-382;
DG Lindburg, BS Durrant, SE Millard and J.E Oosterhuis, 'Fertility assessment of cheetah males with poor seminal quality', Zoo Biol. vol 12, 1993, pp 97-104; DF Keet, NPJ Kriek, M-L Penrith and A Michel, 'Tuberculosis in lions and cheetahs', in J.van Heerden, (ed) Proceedings of a Symposium on lions and leopards as Game Ranch Animals, South African Vet. Ass, Onderstepoort. 1997.

41 Munson et al., 1998; Kriek et al., 1998; van Vuuren et al., 1998; Lobetti et al.,
1998; Terio et al., 1998; Picard et al. 1998 (See entry xxx iii above for these entries). TM Caro, Cheetahs of the Serengeti Plains - Group living in an asocial species. Chicago: The Uni. of Chicago Press, 1994.

42 O'Brian, 1998, (See endnote xxxv).

43 KA Marnewick, and D Cilliers, 'Range use of two coalitions of male cheetahs, Acinonyx jubatus, in the Thabazimbi district of the Limpopo province, South Africa,' South African Journal of Wildlife Research vol 36, no 2, 2005, pp 147-151. 